\title{
Wetland management in Bangladesh: A study on Beel Bakar
}

\author{
Shoumo Khondoker ${ }^{1,3}$, Md. Lokman Hossain ${ }^{2, ~}{ }^{\text {, }}$, Khondoker Azizul Hoque Moni ${ }^{3}$ \\ ${ }^{1}$ Department of Fisheries and Marine Bioscience, Jessore University of Science and Technology, Jessore 7400, Bangladesh \\ ${ }^{2}$ Department of Global Change Ecology, Faculty of Biology, Chemistry and Geosciences, University of Bayreuth, D-95440 Bayreuth, \\ Germany \\ ${ }^{3}$ Ulashi Sreejony Sangha, Jessore 7400, Bangladesh
}

\section{Email address:}

shoumo100429@gmail.com (S. Khondoker), lokmanbbd@gmail.com (M. L. Hossain), uss.jessore@gmail.com (K. A. H. Moni)

\section{To cite this article:}

Shoumo Khondoker, Md. Lokman Hossain, Khondoker Azizul Hoque Moni. Wetland Management in Bangladesh: A Study on Beel Bakar. Agriculture, Forestry and Fisheries. Vol. 3, No. 4, 2014, pp. 320-328. doi: 10.11648/j.aff.20140304.25

\begin{abstract}
Being a riverine country, Bangladesh maintains a large volume of water by its different channels like river, canal, beel, haor, baor, lake and so on. Beel is one of the ancient types of water body in the context of Bangladesh. Among all the types of water bodies existing in Bangladesh, beel is obviously a fascinating one due to its biodiversity and ecological importance in local and national perspective as it contains and passes significant amount of water connecting with river channel which ultimately goes to the sea. The Beel Bakar is a small beel in the southern part of Jessore District of Bangladesh. This study initiated to reveal the existing situation of the aquatic biodiversity of the Beel Bakar along with identifying the past and present water management system, the socio economic aspect of the beel dependent fishermen and possible future steps. The study was carried out through mix group discussion, focus group discussion, key informants interview, direct observation and household survey. The study revealed that once this beel was rich in biodiversity and important for local fisheries. Though a considerable part of the beel and its floodplain is under gher culture, still there is scope to ensure protection and to enhance livelihoods of fisher community. In spite of the degradation of natural habitats of fishes, still 19 species of fishes were observed in the beel as well as some non fish organisms like snail, crab, mussel, frog, migratory and native birds. The study also found that excessive gher culture practice and possession of non fishermen over the water body are the main constrains of the beel. Most of the fishermen live in semi concrete house and vast majority of them have debt to bank or cooperatives. Experts and local fishermen both suggested ensuring the access of real fishermen in Beel Bakar and the Mukteswari River to improve their circumstances.
\end{abstract}

Keywords: Wetland, Beel, Ecosystem, Fisheries, Floodplain, Water Management

\section{Introduction}

Wetlands play a crucial role in maintaining the ecological balance of ecosystems. However, exponential growth of population, unplanned land use, intensive agriculture, overfishing, siltation, pollution, rapid urbanization, lack of intra-sectoral coordination, lack of awareness, etc. play a tremendous impacts on both biotic and abiotic components of wetlands [1]. Nishat [2] pointed out that the degradation of wetlands in Bangladesh were mainly due to: increase of population and expansion of human habitats; expansion of agriculture and subsequent conversion of wetlands through drainage into rice fields; flood control and irrigation project for enhancement of agricultural productivity; national, local and rural infrastructures like ill-planed roads; narrow culvert etc.; over-felling of wetland trees; over-grazing by livestock; over-fishing and associated disturbances; siltation due to degradation of watershed areas which are often trans-boundary in nature; indiscriminate control/ regulation / use of water flows of main river systems in upper riparian; and pollution of water due to industrial, urban, agrichemical and other types of pollutants including pollution from trans-boundary sources. Wetland provides habitat for a variety of resident and migratory waterfowl, a significant number of endangered species, and a large number of commercially important species. Almost 50\% of the country's people are directly dependent on wetlands resources [3]. Bangladesh is estimated to possess seven to eight million ha of wetlands in the form of permanent rivers and streams (0.48 Mha), estuarine and mangrove swamps (0.61 
Mha), shallow lakes and marshes (0.12-0.29 Mha), large reservoirs (90,000 ha), small ponds and tanks (0.15-0.18 Mha), shrimp ponds (0.09-0.115 Mha) and seasonally flooded flood plains (5.77 Mha) [2].

Beel is referred to surface water body that accumulates surface runoff water through internal drainage channel [4]. Beels are important wetlands and regarded as valuable fish and wildlife habitat [4,5]. In the active floodplains of the Surma-Meghna, the Brahmaputra-Jamuna, and the Ganges-Padma river systems, there are several large and small beels. In Bangladesh, there are thousands of beels of different sizes. Most of these large beels have shrunk quite considerably in recent decades [4,5]. Akonda, [6] and Khan et al., [7] recorded that total area of beels and haors in Bangladesh is 1142 ha.

Beels and wetlands have not yet received proper attention in our country. In the 2011-12 fiscal year beel fisheries provided 85,208 metric tons natural and culture fish production where production was $746 \mathrm{~kg} / \mathrm{ha}$ [8]. This plays a significant role in fulfilling the demand of Small Indigenous Species (SIS) and other viable species. These fisheries aspect connects directly with the livelihood of a huge number of fishermen and other people's dependant on the beel. Livelihood of real fishermen is immersed with debts, sorrows and many social and economic restraints. Though there are few initiatives but they are not adequate and in many cases not practical due to influence of vested people and as those approaches are not participatory. Usually beel dependent people are two types: farmers and real fishermen. Former one is based on individual property ownership pattern whereas, later one is based on common property management. Value wise paddy is produced more in the beel compared to production of natural fisheries. Price wise value of fish produced from the beel exceeds the value of rice production. Again cost for agricultural activities is huge thus net benefit is very marginal compared to its investment whereas, the cost of management and harvest in natural variety is very low compared to its nominal investment. Many parts of the floodplain of the beel have been converted to gher (a small confined area mainly used for aquaculture but sometimes agricultural product during dry season). There are benefits and detriments of gher fish culture over the natural fisheries and agriculture. Direct income and scope for employment are available there, thus some people manage ghers and living better life but their number is very few. This system has led to negative impact on the environment too. Livelihoods of the real fishermen of this beel dependent are very measurable. Some of them tried to adjust with other work but could not cope very nicely. Only few fishermen were able to take lease of land and doing fish culture. Most of the fishermen still prefer that they get an ensured access of the Mukteswari River which is their last resort. The study of Ahmed, et.al., [9] ; Nishat, [2]; Gnauck and Islam, [10]; Islam, [11]; Islam and Gnauck [12]; Islam and Gnauck, [13]; Islam and Gnauck, [14]; Islam, [15]; Islam and Gnauck, [16] ; Akonda, [6]; Khan et al., [7]; and Barbier et al., [17] depicts the wetlands resources in Bangladesh, their present situation, causes of degradation and management aspects. No comprehensive study yet undertaken to assess the past and present situation of Beel Bakar. Therefore, it is necessary to assess the present situation, existing livelihood, fisheries resources as well as the current management practice of beel Bakar so as to summarize the problem and recommend prospects. The study attempts to assess the present and past status of Beel Bakar, Monirampur, Jessore, Bangladesh. The study also reveals the state of the livelihoods of real fishermen in the context of converting the floodplain to the fish culture gher.
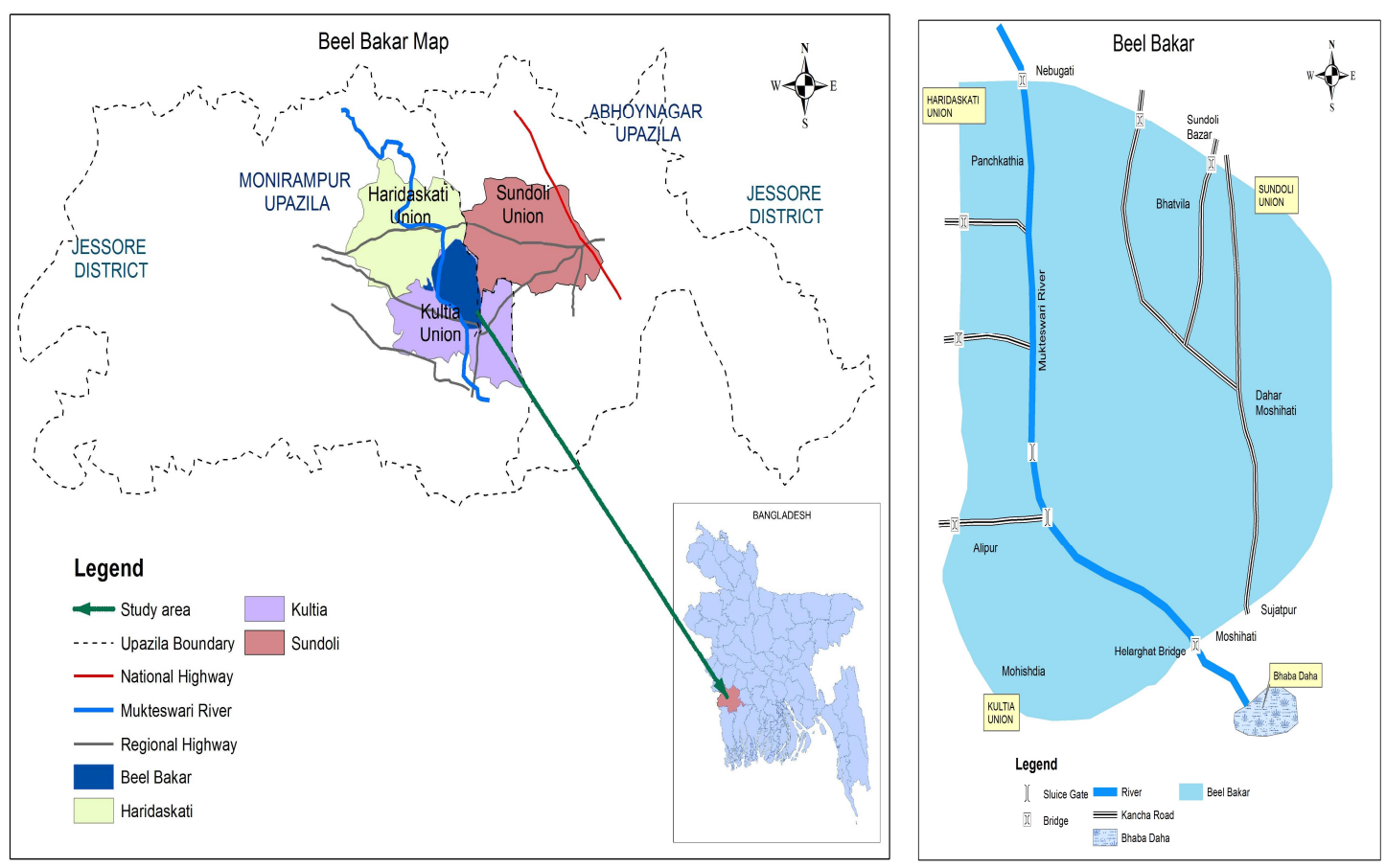

Figure 1. Study area (Beel Bakar covering the surrounding area of Mukteswari River) 


\subsection{Study Area}

The Beel Bakar is one of the important beel under the Dakatia Beel Cluster and one of the first beels under the Mukteswari River system. The beel is situated mostly north of the Moshihati Bazar and south of the MonirampurAbhoynagar road. The Mukteswari River runs through it from north to south and western side of the river belongs to Monirampur Upazilla (sub-district) and eastern side is under Abhoynagar Upazila. Haridashkati and Kultia are two unions (group of nearby villages) in which the beel is situated. To choose this beel as study site is relevant in this way that, it represents the maximum beel of Jessore-Khulna region and having similar ecosystem pattern, but it needs several interventions which should be come out from this initiative. Moreover, geographically it is a very important beel as it has connection with people of both Monirampur and Abhaynagar Upazilla of Jessore district, Bangladesh. With the present changing situation, it is difficult to identify the beel area though major part is reasonably deep and goes under water during wet season. In dry season, water remains in the river and canals and also in low depressions. The floodplain and catchment area is quite big. It is estimated that the Beel Bakar is having an area of about 1750 ha including its floodplain.

\section{Methodology}

The study was designed based on Focus Group Discussion (FGD), Key Informant Interview (KII), direct observation and household survey. Three FGDs were conducted with local fishermen and two with farmers. One mix group discussion with diverse professions was also accomplished to get some discrete data. Six KIIs were performed with two social workers, a teacher, an old gher operator and two gher owners. Forty fishermen's households were surveyed to know their socio economic condition in present days. To get proper data from this survey, question about their daily income pattern, family size, age group, alternative income source, ownership of land, household type, diet, loan, sanitation, drinking water, mobile phone use, medical service and some property related information were gathered which eventually resulted in a portrait of fishing community's life in study area.

\section{Result and Discussion}

\subsection{FGD and KII Findings}

\subsubsection{Past and Present Water Management}

To support Green Revolution water management interventions were achieved through number of activities in this area also. Construction of 21 vent flap gate type sluice gate known as Bhabadaha Sluice gate was made on the Mukteswari River. Apart from it, numbers of sluice gate for water control were constructed upstream and laterally to adjoining areas. Such structures in the downstream were considered to prevent entry of saline water. With a longer period impact of stopping tidal water gradually invited deposition of silts and eventually introduced water logging to particular beel and later extended over to most of the beel and river network of the region. After having the bitter experience of longer period water logging, with the introduction of Tidal River Management (TRM) concept, remedy was observed. Now like many other beel, beel Bakar becomes waterless in dry season. However, conversion of many areas of the beel into gher system limited the return to previous system with a result of inequity of the resources in the form of advantages went to non target people. Many local farmers suggested that, if water release properly through the Bhabadaha Dam (sluice gate), the situation would be nice. They also opined for an additional option of water to divert to Bhairab River (River near Noapara of Jessore district) through Fultala area. They also suggested for re-excavation of Amdangar Khal and Boyrar Khal. It should be noted that unless excavated soil is properly managed, excavation or re-excavation would bring no positive outcome.

\subsubsection{Situation of Gher and Aquaculture}

Initially Gher was done in water logged condition by few people in the beel periphery. Later some people introduced it to trap wild fishes. Now there are three types of ghers:

- Seasonal ghers, mostly done fish culture in wet season and paddy in the dry season usually without any trench.

- Seasonal ghers but, mostly with trench so that, it is possible to fish is in considerable part. This type has two different patterns namely; i) Relatively medium and smaller sized; ii) Very big in size, mostly combining several plots

- Perennial ghers where scope for paddy cultivation hardly available or operators are mostly interested in fish culture.

Apart from gher fish culture, there are number of perennial and seasonal ponds where fish culture is going on. Water retention in the ponds of north-western areas was found poor and suitable for seasonal fish culture.

\subsubsection{Status of Fishermen Livelihoods in the Context of Changed Situation}

Earning and Debt: Most of the fishermen earn 100 to 200 BDT per day only. Thus, monthly average income stands 3000 to 6000 BDT (40-80 US\$) which is very poor. They cannot manage to maintain their family not even to meet basic requirements. Loan becomes a part and parcel of their life due to low income. Threshold capacity to take loan and loan recovery (returning) are also in very measurable position. Before returning a loan another loan is required.

\subsection{Household Survey Findings}

Fishermen villages are conspicuous and isolated. Two villages are in the western side, one in the north and others are in the eastern side. It was observed that all the respondent fishermen are Hindu and lead a low profile life style, although they have a satisfactory water and sanitary system.

\subsubsection{Religion, Family Size, Age Group and Daily Income}


As per household survey, it was found that traditional fishermen are mostly Hindu in religion. Maximum (53\%) respondents (fishermen) are within 31-50 years old, followed by $40 \%$ above 50 years and $7 \%$ range $20-30$ years (Fig. 2). The study also revealed that majority (65\%) of the respondents are very poor whose, average daily income ranged 100-200 BDT. Only 17\% respondents earn above 300 BDT per day (Fig. 3). Very big family size (more than 6 family members) is $15 \%$ (lowest) whereas, small household size ( $1-4$ members) is $25 \%$. However, medium household size (5-6 members) is maximum $(60 \%)$.

\subsubsection{Ownership of Land, House Type, Alternative Income Source and Sources of Loan}

Majority (68\%) of the respondents live in semi concrete house followed by $17 \%$ in concrete and $15 \%$ in earthen house respectively (Fig. 4). The study revealed that $100 \%$ respondents have own land to construct their house. Most of respondents depend on loan from NGOs and bank. Highest (40\%) respondents receive loan from NGOs, followed by $15 \%$ from bank and $7 \%$ from both bank \& NGOs. However, significant $(38 \%)$ proportions of the respondents are not depending on loan from any sources (Fig. 5).

\subsubsection{Alternative Income Source and Status of Fish and Meat in Consumption}

In rainy season major part of the farmers and local people work in fish ghers and do fishing in little open beel portion. In addition to that many of them work as day laborers, rickshaw/van puller etc. Usually they earn 100-150 BDT per day. About $93 \%$ respondents take fish nearly every day. Only $2 \%$ household takes fish a day or two per week (Fig. 6). Reversely, not a single household take meat every day (Fig. 9). The study also revealed that fish from beel in the diet is still not diminished. Twenty percent fish in their consumption comes from beel, but most of them (47\%) come from river source (Fig. 10).

\subsubsection{Status of Drinking Water, Use of Mobile Phone, Sanitary Latrine and Medical Service}

The study revealed that all the households use underground water for drinking, no one use water from river or tanks. No one of the respondents was found who does not have mobile phone set (Fig. 11). Most (72\%) of the households have ring slab toilet, whereas, $25 \%$ use concrete and hygienic sanitary latrine. Only 5\% household uses service of health complex whereas, $40 \%$ gets medical treatment from local practitioner (usually pharmacy person) (Fig. 12).

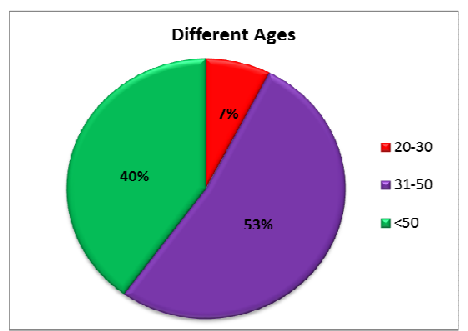

Figure 2. Age group of the respondents in Beel Bakar

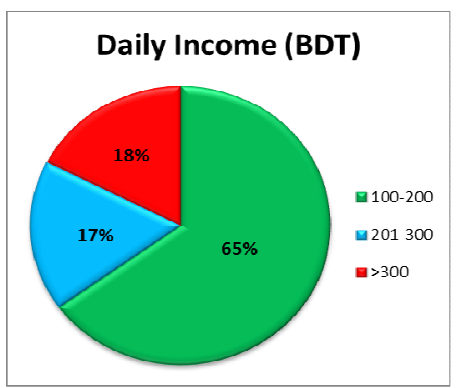

Figure 3. Daily income of the respondents in Beel Bakar

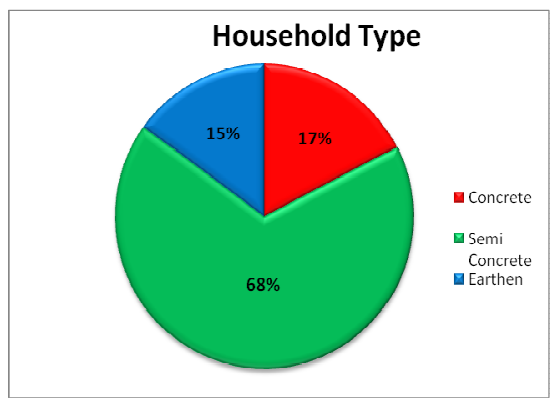

Figure 4. House type of the respondents in Beel Bakar

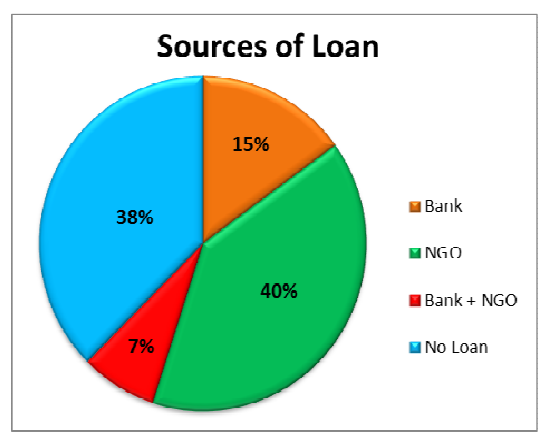

Figure 5. Sources of loan receive by the respondents in Beel Bakar

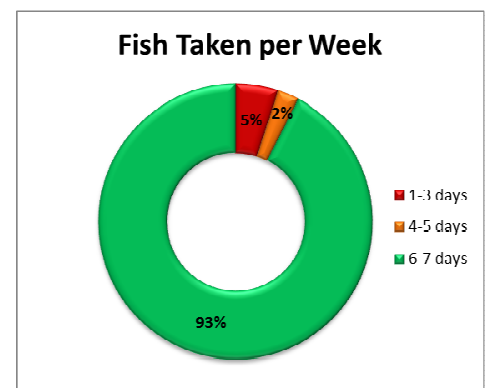

Figure 6. Fish consumption pattern of the respondents in Beel Bakar

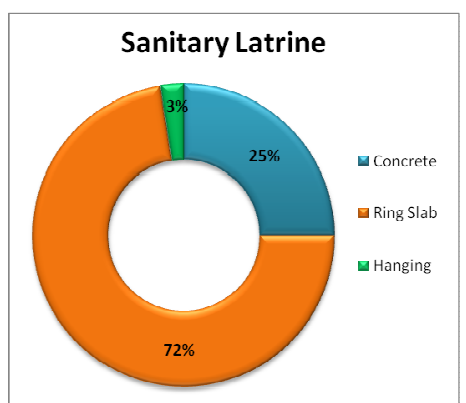

Figure 7. Household's sanitary latrines use in Beel Bakar 


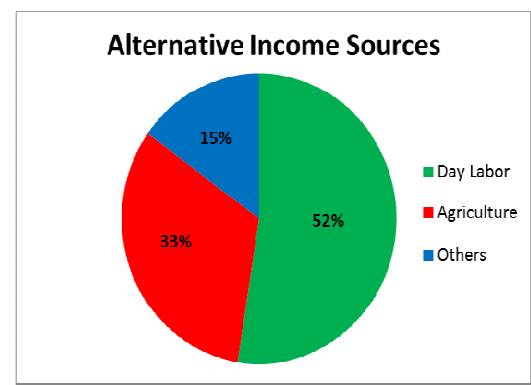

Figure 8. Household's alternative income sources in Beel Bakar

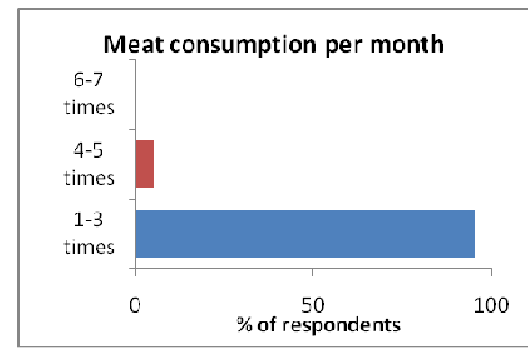

Figure 9. Household's meat consumption pattern in Beel Bakar

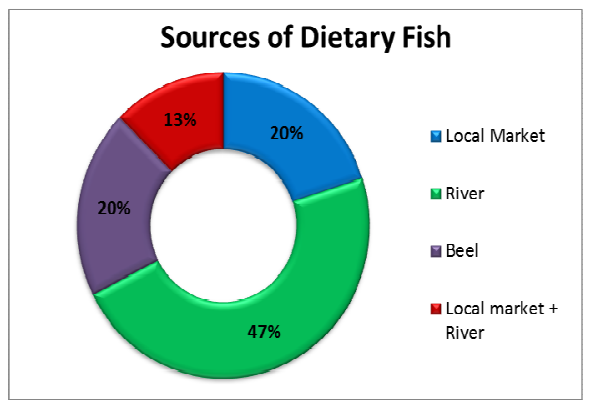

Figure 10. Household's sources of dietary fish in Beel Bakar

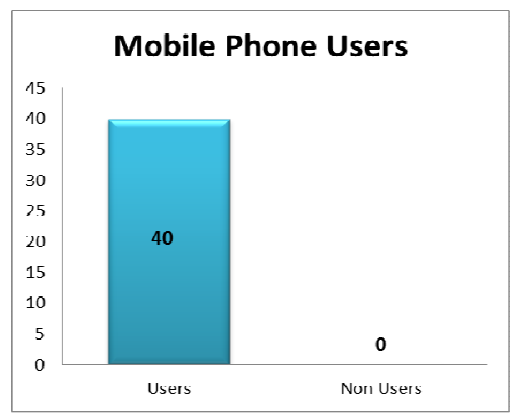

Figure 11. Mobile phone users in Beel Bakar

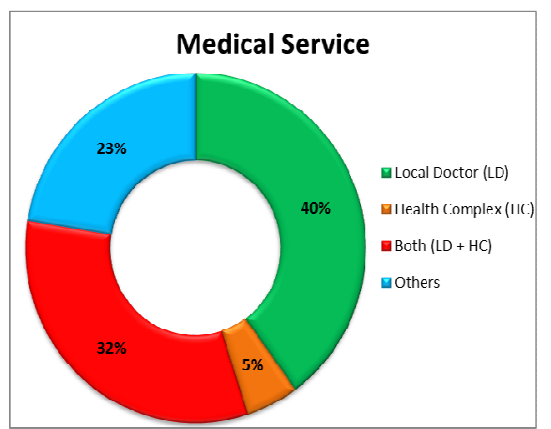

Figure 12. Sources of medical service in Beel Bakar

\subsection{Limiting Factors for Propagation of Beel Fisheries in Bangladesh}

Gher system is the main barrier for the propagation of Beel fisheries and maintaining fish biodiversity. For this, proper management cannot put in place. Introduction of different interventional tools and activities cannot be established like fish sanctuary, habitat restoration and swamp forestry development. Each gher has its own boundary and it stops regular water flow and also restricts flow of nutrition. So, fish cannot move in a natural manner. Sometimes it cannot reach its breeding ground. The over population of some aquatic weeds also help to fall the water quality and eventually the fish propagation. This is associated with making the water stagnant and transparent which is a resultant of excessive man-made intervention.

\subsubsection{State of Conflict and Possible Resolution: Fishers and Farmers}

Usually conflict remains within two professional groups namely; fishers and farmers. Surprisingly, in Beel Bakar there is no conflict between them. This is because traditional fishers are cornered so much that society does not count their sayings. On the other hand, farmers are also cornered by fish culturist.

\subsubsection{State of Conflict and Possible Resolution: Fishers and Aquaculturists}

Fishermen are silent but do have long term conflict with gher fish culturist. This is because they are grabbing most of the floodplain where fish grow. Encroachment to the river is also alarming. Many side canals are interrupted by ghers in such a way that fish movement, breeding, grazing are hardly possible. Fishermen are not in a position to raise their issues in front of the fast growing fish farmers and outside investors as it appears that there is no issue. It is apparent that, more serious conflict or contradiction is going to take place between environment and the present trend of development.

\subsubsection{Beel Fisheries and Fishermen's Livelihoods}

Every beel needs to maintain its open water fisheries for ensuring livelihoods of traditional fishermen. Control of the resources should not go to the person who has the control over resources other than beel also. Khas boundary needs to be demarcated and encroachment needs to be stopped.

\subsubsection{Fish Fry Release and Future Access Status}

Fishermen claimed that the fish fry releasing in open water by the line agency is being diverted by the influential to their fish ghers instead of open beel and rivers. They demanded that program should be implemented in the river. A matter of concern also envisaged that situation has come to such a position that in case fish fry is released in the river, the influential may capture the position or restrict real fishers in managing resources in the river. Thus, there may be a risk of losing the ruminant accessibility of the water body. 


\subsubsection{Reasons of Degradation of Fish and Fisheries Resources Including Habitat Quality}

- Role of insecticide/pesticide in disappearing fish

- Affect of pesticides and fertilizers

- Limiting fish breeding and propagation

- Leaving no fish to breed next year

- Agricultural practices without consideration of fishermen issues

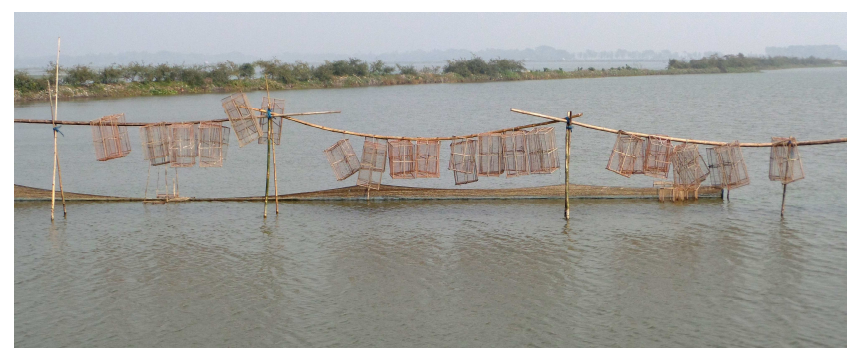

Figure 13. Gher operation in Beel Bakar

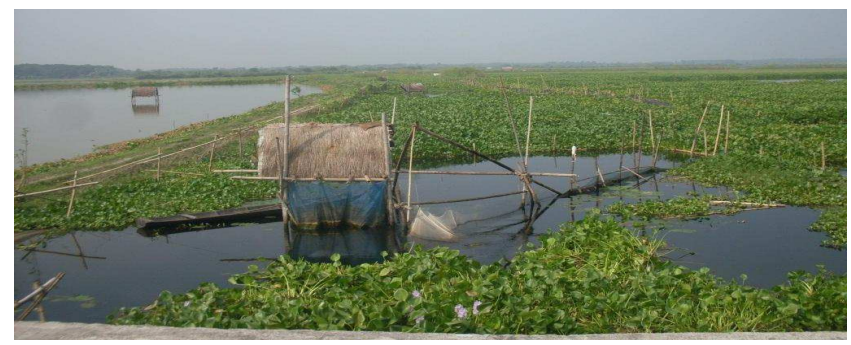

Figure 14. Present Scenario of Beel Bakar

\subsubsection{Problems of the Farmers}

- Now-a-days paddy production is good than earlier, but the production cost is comparatively high.

- Gher practice makes a large portion of the beel busy in fish farming. This hampers the agriculture production of the beel area.

- Gher operators are rich people, thus expansion of gher farming is replacing small scale agriculture.

\subsubsection{Gher Culture Status, Impacts and Solution}

The rapid expansion of the gher construction should be controlled considering its carrying capacity in the beel by maintaining ecosystem functionality. As many people are interested in expansion of gher but significant number of people is now aware of the impacts of gher on beel ecosystem. Solution is needed balancing demand and ecosystem based approach.

Local level planning should come with an outcome of planned zoning of the beel with recommended extent and pattern of ghers if needed. Following points may be considered as solution:

- Ghers should not be continuous or clusters. There should be adequate intervals.

- Ghers should be constructed with appropriate set back distance from the bank of the river or canal.

Local level problem with gher culture

- Gher owner hires the labors and guards from outside of beel area. People from South (Keshabpur and
Monirampur town side) mainly regulate the gher business.

- Local people are deprived of the chance of getting employment from gher.

- The people, who own the ghers, are not real fishermen. This is why; they don't think of the natural habitat of the fish and kill the unwanted species (natural species) for culture purpose.

- Due to gher culture, agricultural production has declined also.

\subsubsection{Fish Migration and Movement Status}

Fish migration and movement takes place up and downstream of the river and also laterally. Due to intervention and with number of fixed ghers and net/ban migration and movement have seriously hampered. Lateral movement and migration also significantly affected due to construction of ghers without any spacing. As grazing area also encroached, number of fish in the river drastically dropped. Few sluice gates are constructed within the Beel Bakar. These are not for paddy cultivation rather, in virtue for the benefit of the gher operators. These sluice gates and ghers constructed in front of bridge/culvert restrict not only fish movement but also contribute in changing water management.

\subsection{Factors need to be addressed for Propagation of Beel Fisheries in Beel Bakar}

\subsubsection{Need for Beel Based Water Management Planning}

Water management should focus natural fisheries and to some extent for agriculture and least for aquaculture/gher farming. Department of Environment (DoE) along with Upazila or District authority should do this planning in participatory manner involving relevant experts. The local level planning should identify and execute how much and which areas of the beel should be identified and take necessary measures to implement it.

\subsubsection{Need for Beel Based Environmental Planning}

Unless beel based environmental planning is done in accordance of the fisheries planning, sustainability of the resource management can be worsen especially in the context of climate change. We do have coastal land use planning and even for greater Dhaka city. District Water Resources Assessment made by LGED by engaging number of consulting firm was a good initiative but could not achieve much due to lack of commitment. DoE, IUCN or relevant organizations should get the power of exercise to do swamp forestry development on land which does not belong to khas land (the land that is owned by the government). Thus, redefining beel boundary based on ecosystem and supported by or in accordance to ecological boundary is required to revert encroachment trends.

\subsubsection{Beel Based Conservation of Fishermen's Rights}

In the river dominated areas, fishermen's rights are river based like the marine fishers go to sea and coast for catching fish. Similarly, in the upland areas where scope of fishing in 
the river is limited but there are number of beels, rights of fishermen should be established beel based. Thus fishermen should get access to habitat area, resources especially natural fisheries.

\subsubsection{National Context of the Demand}

The problems, issues, challenges are little different in this beel compared to many other beels. But this is very important to know the status and process of changes of this beel as in coming days many beels may become like this. For this reason the study findings would be useful in the national context. On the other hand, demand to promote livelihoods of the fishermen is not the demand of this beel only but it should be a national demand.

\subsection{Base Situation}

\subsubsection{Hydrology and Morphological Set Up}

The Mukteswari River flows through this beel. There are number of khals (small pass way of water) and small tributary rivers also. Rain water comes from the upstream through the river and other inlets and rainfall to the catchment are main source of water. Tidal water used to reach the beel earlier but due to different interventions it is not reaching. The slope of the beel is from the north-west and north-east to the south. Thus southern part of the beel and floodplain are deeper and northern, north-west part are shallow. Few parts of the beel are with perennial water and rest is seasonally flooded. Once upon a time (about 15 years ago even) it had normal beel characteristics, later experienced with longer period water logging and recently water logging is over due to TRM process in the adjoining beel and downstream part. The beel and its floodplain are having later connectivity too apart from northern side. In the downstream it is connected with the same river but a different name called Hari River. Water has to pass through the 21 vent BWDB Bhabadaha sluice gate. Ultimately the water flows to the Sundarbans and to the coast.

\subsubsection{Biological Set $U$ p}

Once, the beel was full of water based resources along with paddy, wildlife and birds. Bird trapping by poachers was a regular scene which indicates richness of the beel in terms of biodiversity. Fisheries were one of the important sectors from which people used to get fishes from the natural sources. Presently, due to change of water management pattern morphology, hydrology and culture pattern have significantly changed. Influential people made ghers for shrimp and white fish culture. Part of the beel, specially its floodplain earlier and now supports grazing of livestock. In the natural system, it prevailed much better earlier invited number of migratory and resident birds. This site was also famous for amphibians, reptiles and mammals. Around 20 fish species are still common [18]. In recent past, number of fish species was about 70. Species which are not available now a days are Boal, Pabda, Sarpunti, Magur. snail, crab, kuchia, frog, snakes are still observed in the beel.
Table 1. Commonly available fishes in Beel Bakar

\begin{tabular}{llll}
\hline SI & Local & Scientific Name & Order \\
No & Name & Puntius spp. & Cypriniformes \\
\hline 01 & Puti & Labeo rohita & Cypriniformes \\
02 & Rui & Catla catla & Cypriniformes \\
03 & Catla & Cirrhinus cirrhosus & Cypriniformes \\
04 & Mrigel & Labeo calbasu & Cypriniformes \\
05 & Kalbaus & Labeo bata & Cypriniformes \\
06 & Bata & Channa striatus & Channiformes \\
07 & Shol & Anabas testudineus & Perciformes \\
08 & Koi & Heteropneustes fossilis & Siluriformes \\
09 & Shing & Oreochromis & Perciformes \\
10 & Tilapia & mossambicus & Channiformes \\
11 & Taki & Channa punctatus & Cypriniformes \\
12 & Tengra & Mystus spp. & Mastacembeliformes \\
13 & Baim & Mastacembelus spp. & Perciformes \\
14 & Bele & Glossogobius guiris & Cypriniformes \\
15 & Mola & Amblypharyngodon mola & Cypriniformes \\
16 & Dhela & Osteobrama cotio & Perciformes \\
17 & Kholisha & Colisa fasciatus & Channiformes \\
18 & Chang & Channa gachua & -- \\
19 & Small & -- & \\
\hline & & &
\end{tabular}

Fishing ghers that were common in this beel are Current jal (net), Vasal jal (lift net), Goga jal, Khewla jal, Arende jal, Koach, Kachari, Khuni, Charo, Nesa, Borsi, Gaze, Pata, Chari etc (Table 2). Aquatic vegetation including water lily and other species (kolmi, helencha, hogla pata) are still present but once used to maintain a healthy food chain. This was mainly dependent on non fish organisms as important steps of the food chain and food web. Both terrestrial and water dependent plants and reeds are still found. Pitali which is one of the swamp plants growing widely. Common birds of this beel are Pankouri, Stork, Finge, Shalik, Doyel, Dongur, Vilabile, Bakchu, Ghu ghu, King Fisher etc. Once the agriculture was with harmony with natural fisheries and wildlife but now it has been transforming to Boro paddy (a native variant of paddy) within the ghers rapidly. Both agriculture and culture fisheries are with rapid acceleration threatening biodiversity and livelihoods of poor people especially the traditional fishermen. In addition of main cereal crops (rice, wheat) non-cereal crops and vegetables like Pumpkin, Cucumber, Cabbage, Broccoli, Cauliflower, Chili, Kohlrabi, Bitter gourd, Petsai etc. are also seen to be grown by the beel areas. Farmers use chemical fertilizers for crop production. Fertilizers used in the study area are Urea, TSP, Zinc and Potash. Inorganic fertilizers are used in the beel are for IRRI crop. Main crop in the beel is IRRI. But in early days the beel was flourished with different vegetables and native paddy variants like Aush, Amon, Boro etc. But due to the introduction of hybrid crops and low production of native crops, farmers became less interested in the production of these crops. In Beel Bakar, no crops were cultivated during 1986 to 2009 due to water logging. From 2010-11 the cultivation was again started. But $75 \%$ of the total beel remains under water all the year round. BRI 28 gives production of 20-25 mound (a local unit which represents $40 \mathrm{~kg}$ ) per bigha (42 decimal) land. About 30-35 mounds paddy per bigha is produced with hybrid variety like 
SL 8, Hira, Sathi, Rajkumar. Fishes cultured in the ghers of Beel Bakar are golda, rui, silver carp, grass carp, black carp, common carp, big head, tilapia, mrigel and some other Indian major carps and Chinese carps.

Table 2. Fishing ghers used in Beel Bakar

\begin{tabular}{ll}
\hline Gher Name (Local) & Major species caught \\
\hline Vasal Jal (Lift net) & All kind of fishes (small to large) \\
Khewla Jal & Punti, Taki, Royna etc. \\
Goga Jal & Mainly big fishes \\
Kachari Jal & Rui, Shol etc. (Mainly medium size species) \\
Khuni & Chingri (Shrimp), Puti etc. \\
Charo (Fish trap) & Koi, Taki, Gutia etc small species. \\
\hline
\end{tabular}

\subsubsection{Social Set Up}

The Beel Bakar is surrounded by many villages namely Mohishdia, Alipur, Poradanga, Padmanathpur, Parualia, Dharmatala, Panchkathia in the western side and Hazirhat, Nebugati, Kucholia, Sundali in the north. Villages of the east are Dhopadi and Hargacha and in the south Moshihati. There are some villages situated within the beel but mostly in its eastern floodplain are Bhatbhila, Danga Mashihati, Dohor Moshihati, Bariadaha, Baje Kultia. Common people are dependent on agriculture, fisheries, aquaculture and small business mainly. Gher fish culture of the beel is mainly controlled by rich and influential people. However, along the catchment boundary especially in the northwest part, medium and small farmers also doing gher fish culture within their small plots. Fishermen belong to several villages. In Mohishdia village, there are about 65 fisher families in the Rajbongshi para (a cluster of inhabitants) alone. Their livelihoods are under extreme threat and vulnerable due to drastic shrinking of open water to aquaculture. There are many non-traditional fishermen. In wet season mostly all person gets involved in fishing for livelihoods and subsistence in nature.

\subsection{Proposed Interventions}

\subsubsection{Fish Sanctuary by the Fishermen Community}

Usually local people in most part of Bangladesh are afraid of conservation as the idea they first get is "Restriction" giving them flavor denying access. Concept of conservation practically means getting resources at a certain level for longer time period instead of higher quantity but for short period. The study was also confronted with this situation in Beel Bakar area. Some of the respondents opined that if conservation effort is taken then where they will catch fish. It seems that all development they have been acquainted is planned and made by officials and imposed to them and the process is not participatory. It was discussed with them in detail and they opined that if the planning process of conservation is made by taking their opinion or process, itself allow them to take decision where to conserve, when to and what to. Then they would be happy and that effort certainly benefits them. It appeared that with full participation of fishermen dependent on the Muteswari
River and the beel can establish Community Based Fish Sanctuary. They are clear about the concept that if they can harvest the outcome of the conservation then no problem in allowing conservation.

\subsubsection{Fish Habitat Restoration of Beel and River}

Restoration of fish habitat mainly consists of re-excavation with proper slope and ensuring management of excavated soil. Apart from this, encouraging regeneration of swamp forest to support fish is important aspect of the habitat restoration. Sometime introduction of recently disappeared fish species considered as part of the process. Though total environment of the beel has been marching towards materialistic development, still there is scope for restoration of the river and adjoining floodplain or beel part also. The process should be designed and monitored by fish habitat restoration expert and executed by fishermen, local organization and related field agencies. A decision on planning process for maintaining a setback distance for gher making from the river and khal even if that is part of private property should come up. So this habitat restoration should be friendly to the ecosystem and environment to benefit fishermen and local people ultimately. Fishermen should not be treated as competitor to the resources of the beel rather it is an advantage of getting service of fishermen at nominal cost in managing resource generation and recommended harvesting process.

\section{Conclusion and Recommendations}

\subsection{Conclusion}

In Bangladesh, about $11 \%$ populations are involved with fisheries sector and this sector contributes $4.39 \%$ to the national GDP. This field deserves more attention by both government and private investors to conserve biological resources and ensure food security. The study reveals that that Beel Bakar desires a better management approach and for its long term effectiveness it should be participatory, mainly with the involvement of local community. Although it lost its diversity in both flora and fauna, the existing species can be conserved by the conservation of beel, its floodplain and Mukteswari River. As around 8450 families are directly and indirectly dependent on the beel, it is also important to restore the wetland for ensuring livelihood of surrounding communities.

\subsection{Recommendations}

- Need to establish rights of the fishermen. Main contradiction with this issue is to ensure the access of real fishermen into Beel resource. The non fishermen/ fish businessmen need to be stopped who degrade the natural part of the beel.

- Recommended river stretch for conservational effort (also suggested by fishermen) is Lokhaidanga, Kultia Bridge to Helar Ghat Bridge, Helar ghat to Bandhar Matha and Lohadanga. 
Recommendations suggested by the fishermen are:

- Fisher folk believe that, they have lost possession over the beel. Now as their only hope they want the river (Mukteswari) free from all side effects and have the access year round.

- They also want to ensure the total fish fries in the river allotted for this area by the Government so that they can harvest/capture them when they are mature.

- Government released fish should be captured by the real fishermen only.

- Access of the non fishermen community need to be restricted in the beel and river.

- It has strongly recommended to keep a setback distance from the river bank to construct gher and also to keep required gap from a cluster of gher to another (not to make continuous) to reduce impact on natural fisheries and aquatic environment.

\section{Acknowledgements}

The authors extend their profound thanks to Ulashi Sreejony Sangha (USS) for giving a scope to conduct this study under CSRL approach. The authors are grateful to OXFAM in Bangladesh for providing financial support to USS in beel movement and the protection of beel dependent people's rights. In addition, special thanks go to Dr. Munir Ahmed, Executive Director, TARA, Bangladesh for his sincere effort during the whole study. Moreover, the authors are thankful to Dipshikha Sangastha (DSS) and its research team (especially Prokash Chandra Dhar, Executive Director, and Mrs. Jyotsna Mollick, Coordinator) for providing necessary information, logistic support during each field trips, household survey and focus group discussions.

\section{References}

[1] Byomkesh, T., Nakagoshi, N., Shahedur, R.Md., 2008. State and management of wetlands in Bangladesh. Landscape and Ecological Engineering, 5(1):81-90. DOI: 10.1007/s11355-008-0052-5.

[2] Nishat A., 1993. Fresh water wetlands in Bangladesh: Status and issues. In: Nishat A, Hossain B, Roy M K, Karim A, eds. Freshwater Wetlands in Bangladesh - Issues and Approaches for Management. Dhaka: IUCN, 9-22.

[3] Islam, S.N., 2010. Threatened wetlands and ecologically sensitive ecosystems management in Bangladesh. Frontiers of Earth Science in China. 4(4):438-448. DOI:10.1007/s11707-010-0127-0.

[4] Banglapedia, 2012. National Encyclopedia of Bangladesh, Asiatic Society of Bangladesh, Dhaka, Bangladesh. Available from URL: http://www.banglapedia.org/HT/B_0429.htm.

[5] Bangladesh Water Development Board (BWDB), 2014. http://www.bwdb.gov.bd
[6] Akonda, A.W., 1989. 'Bangladesh' in DA Scott ed, A Directory of Asian Wetlands, IUCN, Switzerland, 1989.

[7] Khan S M, Haq E, Huq S, Rahman A A, Rashid S M A, Ahmed H (1994). Wetlands of Bangladesh. Dhaka: Holiday Printers Limited, 1-88.

[8] Department of fisheries (DoF), 2013. DoF Magazine, Department of Fisheries, Government of People's Republic of Bangladesh, Dhaka, Bangladesh.

[9] Ahmed, I., Deaton, B.J., Sarker, R., Virani, T., 2008. Wetland ownership and management in a common property resource setting: A case study of Hakaluki Haor in Bangladesh. Ecological Economics, 68(1-2):429-436. DOI: 10.1016/j.ecolecon.2008.04.016.

[10] Gnauck A, Islam S. N., 2004. The Threatened Mangrove wetlands ecosystems in Bangladesh: A case study on the Sundarbans. In: Proceedings of 7th INTECOL International Conference on Wetlands 2004, Utrecht. The Netherlands: Universiteit Utrecht Press, 109

[11] Islam S N, 2007. Water salinity and thresholds for the protection of mangrove wetland ecosystems in the Sundarbans Region. In: Ganuck A, ed. Modellierung und Simulation von Ökosystemen (Modelling and Simulation of Ecosystems Journal). Aachen: Shaker Verlag, pp.187-201

[12] Islam S N, Gnauck A., 2007a. Effects of salinity intrusion in mangrove wetlands ecosystems in the Sundarbans: an alternative approach for sustainable management. In: Okruszko T, Jerecka M, Kosinski K, eds. Wetlands: Monitoring Modelling and Management. Leiden: Taylor \& Francis/Balkema, pp.315-322.

[13] Islam S N, Gnauck A., 2007b. Salinity intrusion due to freshwater scarcity in the Ganges catchment: a challenege for urban drinking water and mangrove wetland ecosystems in the Sundarbans region, Bangladesh. In: Proceedings of 6th World Wide Workshop for Young Environmental Scientists 2007, Paris. Paris: CEREVE Enpc, 20-30.

[14] Islam S N, Gnauck A., 2008. Mangrove wetland ecosystems in Ganges-Brahmaputra delta in Bangladesh. Front Earth Sci China, 2(4): 439-448.

[15] Islam S N., 2008. Cultural landscapes changing due to anthropogenic influences on surface water and threats to mangrove wetlands ecosystems: a case study on the Sundarbans, Bangladesh. Dissertation for the Doctoral Degree. Cottbus: Brandenburg University of Technology, $1-179$

[16] Islam S N, Gnauck A., 2009a. Threats to the Sundarbans mangrove wetland ecosystems from transboundary water allocation in the Ganges basin: a preliminary problem analysis. International Journal of Ecological Economics \& Statistics, 13(W09): 64-78.

[17] Barbier, E., Acreman, M., and Knowler, D., 1997. Economic valuation of wetlands: a guide for policy makers and planners. Ramsar Convention Bureau, Gland.

[18] Rahman, A.K.A., 2005. Freshwater fishes of Bangladesh. Zoological Society of Bangladesh, Dhaka 366pp. 